\title{
MÉTODOS DE ANÁLISE DE ASSUNTO EM FOTOGRAFIAS: ESTUDO NO ÂMBITO DO ENSINO DA REPRESENTAÇÃO DA INFORMAÇÃO
}

\author{
MÉTODOS DE ANÁLISIS DEL TEMA EN \\ FOTOGRAFÍAS: ESTUDIO DE LA ENSEÑANZA DE LA \\ REPRESENTACIÓN DE LA INFORMACIÓN
}

Ana Carolina Simionato*

\begin{abstract}
RESUMO:
Introdução: O documento fotográfico é considerado por seu valor histórico e por seus elementos próprios de realidade direta que são transmitidos pela sua sintaxe visual. Propõe-se a reflexão de como os métodos de análise de assunto em fotografias devem fazer parte da composição do ensino da representação nos cursos de Biblioteconomia e Ciência da Informação na Universidade Federal de São Carlos (UFSCar). Objetivo: É objetivo deste trabalho apresentar um panorama das principais orientações para a atribuição do valor do metadado de assunto no tratamento de fotografias, inserido ao âmbito do ensino na graduação de Biblioteconomia e Ciência da Informação. Metodologia: O levantamento bibliográfico realizado abordou orientações acerca da representação de fotografias, subsidiando a natureza teórica, exploratória e qualitativa do trabalho. Resultados: Os resultados mostram que as características de assunto apresentam uma gama de possibilidades e que, mesmo assim, não retiram a subjetividade de uma imagem. Conclusões: Considera-se que a utilização dos instrumentos e orientações para o conteúdo aumenta a consistência dos metadados de assunto para os sistemas de localização, acesso, uso e reuso de fotografias, em bancos de dados, catálogos e outras formas de armazenamento imagético.
\end{abstract}

Palavras-chave: Fotografia. Análise de assunto. Organização da informação. Representação da informação. Imagem.

*Doutora em Ciência da Informação pela Universidade Estadual Paulista Júlio de Mesquita Filho - Marília. Docente da Universidade Federal de São Carlos. E-mail: simionato.ac@gmail.com 


\section{INTRODUÇÃO}

Por muito tempo o documento em texto foi a principal forma de comprovação de um fato ou informação, no entanto, com a criação da fotografia e de outros recursos informacionais no século XX, o escopo da tipologia documental foi revisitado para inserção de novos conceitos e objetos informacionais.

A fotografia retrata características e fragmenta momentos, por essa razão, o documento fotográfico é considerado por seu valor histórico e por seus elementos próprios de realidade direta que são transmitidos por sua sintaxe visual.

Muitos se utilizam desse tipo de recurso informacional como objeto de estudo e registro de uma época e seus costumes, além disso, de características essenciais de pessoas, famílias e instituições. Ou seja, uma forma expressiva de pesquisa, em respeito aos aspectos religiosos, culturais, sociais, econômicos ou mesmo artísticos.

Nesse sentido, a fotografia pode ser diferenciada em dois tipos: autoral e documental. A autoral refere-se ao desenvolvimento do valor cultural, em que o fotógrafo é considerado um mediador que seleciona personagens e objetos em um espaço que será 'externalizado' como uma lembrança. Já a documental, como fonte de informação, acrescenta diferentes análises da história, na qual os elementos a serem representados devem estar claros. "[...] a fotografia revoluciona a memória, multiplicando-a e democratizando-a, dando uma precisão e uma verdade que permitem guardar a memória do tempo e da evolução da sociedade" (LE GOFF, 2003, p. 460).

Ao utilizar-se da fotografia documental, deve-se repensar o seu processo de construção, pois aquela imagem reflete as "[...] múltiplas interpretações, nas diferentes leituras que cada receptor dela faz num dado momento; tratamos, pois, de uma expressão peculiar que suscita inúmeras interpretações" (KOSSOY, 2002, p. 38).

A partir de seus elementos de construção, a informação fotográfica traz uma subjetividade que no tratamento documental é considerada como um 
desafio para muitos profissionais da informação. Assim, as normativas para a representação de fotografias reproduzem formas mais detalhadas para sua análise documental, antecedente ao processo de representação.

A representação de assunto torna-se destaque por sua necessidade de discussão. Os instrumentos e metodologias disponíveis auxiliam na composição do metadado de assunto, no entanto, a definição ainda traz formulações não representativas ao tipo de documento.

Nesse cenário, é possível refletir como os métodos de análise de assunto em fotografias devem fazer parte da composição do ensino da representação temática nos cursos de Biblioteconomia e Ciência da Informação. Neste artigo objetiva-se apresentar um panorama das principais orientações de representação para atribuição dos valores ao metadado de assunto no tratamento de fotografias, e descrever para o âmbito do ensino na graduação de Biblioteconomia e Ciência da Informação.

Dessa forma, os procedimentos metodológicos utilizados a partir do levantamento bibliográfico realizado, que abordou os temas sobre fotografia, imagem fotográfica, e sobre orientações acerca da representação de fotografias, subsidiando a natureza teórica, exploratória e qualitativa em relação à dinâmica, ao mundo e ao sujeito, em razão da interpretação e compreensão dos fenômenos sobre os métodos para o tratamento temático da fotografia.

\section{ORIENTAÇÕES PARA O TRATAMENTO TEMÁTICO DA FOTOGRAFIA}

A partir da invenção da câmera escura no século XIX e a garantia de fixação da imagem em uma placa para processos comerciais, que, em 1839, era conhecida como daguerreotipo, o registro fotográfico popularizou-se com câmeras portáteis de custo reduzido que hoje foram, inclusive, transpostas ao meio digital.

Consequentemente, com o aumento do número de câmeras a proporção de registros fotográficos cresceu exponencialmente, dessa forma, tomaram proporções que possibilitaram o reconhecimento de seu valor histórico e 
cultural, justificando a preservação e conservação pelas unidades de informação. Com o armazenamento das coleções de fotografias e acervos culturais em centros de informação, também surgem novas reflexões para representação desse tipo de recurso informacional.

As câmeras digitais e suas imagens lidam fluentemente com os atributos e valores que caracterizam um recurso informacional, no caso, os recursos imagéticos. No entanto, os elementos descritivos são intrínsecos a qualquer tipologia de material, sendo em ambiente digital ou tradicional. É possível dizer que os metadados são as formas mais simples de descrição em ambientes informacionais digitais, são compostos por atributos e valores, previamente definidos por uma forma metodológica para composição de um padrão de metadados. No entanto, nas fotografias tradicionais, os profissionais devem escolher a melhor forma para descrição das informações técnicas e, no caso, independentemente do meio, devem elucidar a representação por assunto

Além disso, como afirmam as autoras Dal'Evedove e Fujita,

[...] muitas das ações subjetivas e particulares dos profissionais da informação decorrem da falta de instrumentos e parâmetros direcionados para a realidade da prática profissional, está altamente dependente do contexto de informação em que o profissional está inserido (2013, p. 22).

A representação pode ser conceituada como um conjunto de convenções sintáticas e semânticas que torna possível descrever as coisas de forma intrínseca e extrínseca, e necessita de padrões para formalizar e adaptar a apresentação prevista e proposta ao usuário, com a finalidade de aperfeiçoar as buscas, o acesso e a localização. Nesse sentido, Smit (1996, p. 29) aponta que

A proposição de uma metodologia de análise da fotografia supõe um entendimento da essência desta, daquilo que a caracteriza, das razões pelas quais e produzida e, sobretudo, das condições em que será utilizada. Em outras palavras, torna-se necessário compreender a imagem fotográfica, enquanto informação a ser tratada e recuperada.

A padronização almejada pelos bibliotecários não é a garantia de uma representação adequada para uma fotografia e os instrumentos de 
representação ainda não oferecem amparo eficiente (SIMIONATO, 2012).

Os códigos tradicionais da área de Biblioteconomia não conseguem abarcar a especificidade da imagem. A exemplo, o Código de Catalogação Anglo-Americano (AACR2) que não apresenta os subsídios necessários para descrição das técnicas fotográficas e do próprio assunto principal. Por isso o profissional deve estar sempre consultando outros padrões de metadados, como o CDWA, VRA Core, Cataloging Cultural Objects, Graphic Materials ou mesmo o catálogo decisório da instituição.

Caso a unidade informacional utilize o MARC 21, nos campos e subcampos disponíveis serão encontrados metadados de assunto no grupo 6XX, correspondendo o 650 ao termo tópico e o 690 ao termo atribuído pela instituição.

A discussão e o tema deste trabalho, concentra-se pelas características das estruturas que são atualmente estabelecidas, muito das informações correspondem a diretrizes para o valor dos metadados, que em muitos casos dificultam a compreensão dos profissionais da informação e ainda, muitos profissionais optam por não seguir a devida padronização de instruções para o preenchimento, assim afetando a interoperabilidade e a troca de registros.

Para os ambientes digitais, a atribuição do assunto também pode ser feita pela folksonomia, definida como uma forma de recuperação que atribui aos usuários a responsabilidade de indicar as tags, por meio de termos da linguagem natural. Dessa forma, os usuários categorizam e indexam temas que julgam relacionados à imagem, contudo, na maioria das vezes, essas tags acabam representando um conteúdo que não é o que foi apresentado. Como Herst et al. apontam "[...] um computador procura as imagens na Internet através de palavras-chave ou tags, porém nem sempre é encontrado o que se deseja; isso acontece, pois, as imagens são encontradas com base nos metadados que as acompanham [...]" (2007, não paginado, tradução nossa).

Vale apontar a necessidade da criação de atributos ou mesmo a atribuição adequada de valores representativos às informações, para que estas se apresentem adequadamente aos usuários, por meio de uma recuperação eficiente e eficaz. Ou seja, os instrumentos para padronização dessas 
informações evitam alguns equívocos como usar 'branco e preto' (um valor descritivo) em um valor temático (SIMIONATO, 2015).

Para evitar isso, é necessário fazer uma análise e uma síntese do conteúdo imagético e, posteriormente, realizar a descrição e a compilação dos metadados. Nesses procedimentos estão inseridas as principais operações da análise documental, sendo ainda incluídos os processos de classificação, indexação e condensação documentária.

Segundo as autoras Boccato e Fujita (2006, p. 90)

A análise documental de imagens deve atender aos preceitos da documentação, refletindo a credibilidade e segurança no momento da recuperação da informação pelo usuário. Atendendo assim ao objetivo central da análise documental, a informação documental deve promover a identificação de materiais informacionais que respondam, de maneira satisfatória, às questões dos usuários e, por outro lado, possibilitar a tomada de decisões sobre a consulta e a escolha de um determinado documento original.

A análise documental deve pautar-se principalmente em uma análise do conotativo concreto (RODRIGUES, 2011). Para interpretação da fotografia deve ser observados os elementos constitutivos da mesma, com termos que sejam claros, exemplo: arquitetura, prefeitura municipal, cidade.

Essa análise, por meio do conotativo concreto, diminui a subjetividade e a descrição do conteúdo. Erwin Panofsky (1979) estabeleceu níveis para análise da imagem que orientam essa subjetividade. Panofsky (1979) apresenta três níveis para a análise de imagem: 1) pré-iconográfico, onde são descritos genericamente os objetos e ações representadas pela imagem; 2) iconográfico, que estabelece o assunto secundário ou convencional ilustrado pela imagem, ou seja, trata da determinação do significado abstrato ou simbólico da imagem, sintetizado a partir de seus elementos componentes, detectados pela análise pré-iconográfica; 3) iconológico, que propõe uma interpretação do significado intrínseco do conteúdo da imagem. A análise iconológica é construída a partir dos níveis anteriores, mas possui influências do conhecimento do analista sobre o ambiente cultural, artístico e social no qual o registro foi gerado.

Inf. Inf., Londrina, v. 22, n. 2, p. 532 - 545, maio/ago., 2017. http:www.uel.br/revistas/informacao/ 
A imagem é, simultaneamente, específica e genérica, segundo Shatford (1986) que, baseado nos níveis de Panofsky (1979), discute a representação da imagem, introduzindo uma distinção entre o tema genérico, específico e sobre. Shatford representa os níveis em categorias, pois, para ele, um usuário pode compreender o sentido pré-iconográfico de uma imagem (por exemplo: rio), mas não consegue entender suas necessidades em termos iconográficos (por exemplo: rio Amazonas).

As categorias de Shatford (1986) representam os questionamentos de: Quem? (seres), Onde? (espaço), Quando? (tempo), Como? (técnica) e O quê? (ação). Estas categorias também foram aplicadas e estudadas por outros autores, que citamos: Smit (1989), Kossoy (2001), Manini (2001) e Maimone e Gracioso (2007).

No trabalho de Costa (2008) as categorias foram também relacionadas com as categorias Personalidade, Matéria, Energia, Espaço e Tempo - PMEST -, ditas como "categorias essenciais", propostas por Ranganathan em 1931. Encontrando, assim, relação entre Personalidade - Quem?, Matéria - O quê?, Energia - Como?, Espaço - Onde? e, por fim, Tempo - Quando?.

Por conseguinte, a análise documental para atribuição do valor aos metadados de assunto contempla outros processos vinculados que envolvem, além das categorias, a indexação. A partir da indexação, processo originário da necessidade de um aprofundamento de conteúdos específicos, é possível identificar o tema de um documento e representá-lo por conceitos, ou seja, transformar a Linguagem Natural - LN - em uma Linguagem Documentária - LD (FUJITA, 2009).

A partir desse processo terminológico são criados instrumentos para padronização de termos; essas orientações variam em seu nível de aprofundamento do conteúdo, bem como em sua forma de padronização terminológica, como exemplo os vocabulários controlados. Estes se destacam por serem sistemas de organização do conhecimento (BOCCATO; RUBI; FUJITA, 2014), que possibilitam a representação dos conceitos identificados e selecionados, mediante a análise conotativa concreta do conteúdo fotográfico.

Dessa forma, os vocabulários controlados estão dispostos em uma 
ordem específica e caracterizam-se por três relações: equivalência, hierárquica e associativa. Quando os termos são estruturados de forma hierárquica, condizem com a formação de um tesauro, que pode ser tanto monolíngue quanto multilíngue, e os objetivos concentram-se em promover a coerência na indexação de conteúdo para facilitar a pesquisa e navegação (HARPRING, 2010).

\title{
3 O USO DO TRATAMENTO TEMÁTICO DA FOTOGRAFIA NO ENSINO
}

Com base nos métodos já apontados no tópico anterior, os alunos do curso de Biblioteconomia e Ciência da Informação da Universidade Federal de São Carlos (UFSCar) foram direcionados a relacionar o campo de estudo com a integração entre a extensão, ensino e pesquisa, desse modo, Castro (2002, p. 51-52) corrobora que,

\begin{abstract}
A pesquisa dará maior compreensão teórica, prática e técnica ao futuro profissional, que compreenderá de maneira mais ampla a natureza, os problemas e as possíveis soluções para as unidades de informação e para os referenciais teóricos da área e, principalmente para definir a favor e contra quem o profissional emprestará seu capital intelectual.
\end{abstract}

Nesse mesmo contexto, a priori, foi necessário um estudo da estrutura formal de representação que contemplasse as propriedades imagéticas e também as características do assunto, tendo como intuito propiciar um ambiente que dê ao futuro profissional a capacidade de ir além do processo reprodutivo.

Para isso as etapas envolvem a pesquisa e o descobrimento de cada particularidade relativa à fotografia. Todo o estudo foi realizado em uma atividade extensionista, intitulada como 'Curadoria de acervos: manutenção, organização e representação de documentos', conjunto as atividades de ensino das disciplinas 'Discurso, História e Memória' e 'Análise das práticas culturais e discursivas' do curso de Biblioteconomia e Ciência da Informação da Universidade Federal de São Carlos (UFSCar).

Para o projeto de extensão foi selecionada uma coleção de fotografias

Inf. Inf., Londrina, v. 22, n. 2, p. 532 - 545, maio/ago., 2017. http:www.uel.br/revistas/informacao/ 
sobre a cidade de São Carlos no período de 1970 a 1989, parte do acervo da Unidade Especial de Informação e Memória (UEIM), localizada no Centro de Educação e Ciências Humanas (CECH) da UFSCar, que objetiva a preservação da memória social brasileira com ênfase na história local e regional, possui uma variedade documental que, em geral, está relacionada a um assunto ou uma personalidade, cujos títulos destacam-se no cenário das Ciências Humanas.

A UEIM possui em seu acervo uma variedade de coleções que incluem arquivos privados, fundos públicos, dossiês, hemeroteca, mapoteca, teses, dissertações e biblioteca de apoio, com diversas coleções fotográficas de temas distintos, da região e da cidade de São Carlos, no estado de São Paulo, incluindo a produção cafeeira, eventos cívicos, exposições, entre outros assuntos.

Durante as disciplinas os alunos vivenciaram a teoria dos preceitos da Biblioteconomia e Ciência da Informação, e ainda, refletiram sobre os procedimentos e afazeres para seu futuro cenário profissional. Entre os pontos de reflexão, esteve a preocupação com a organização da informação por meio da identificação de descritores e da composição de resumos nos álbuns fotográficos disponibilizados.

$\mathrm{Na}$ representação das fotografias, de forma geral, os metadados foram adaptados com base no Manual para catalogação de documentos fotográficos, da Biblioteca Nacional, publicado em 1998. Os metadados utilizados para a catalogação de fotografias nas disciplinas foram: título atribuído, local identificado, data da imagem, indicação de responsabilidade, quantidade e descrição genérica das imagens, designação específica, formato, cromia, legibilidade, conservação, palavras-chave e resumo. Logo, os metadados para o campo de assunto foram: palavras-chave e resumo.

Com as características de assunto, anteriormente ressaltadas, apresenta-se uma gama de possibilidades que, mesmo assim, não retiram a subjetividade de uma imagem. Para demonstrar isso, a Figura 1 apresenta um exemplo dos registros da coleção selecionada. 
Figura 1 - Primeira colocada na exposição de Orquídeas

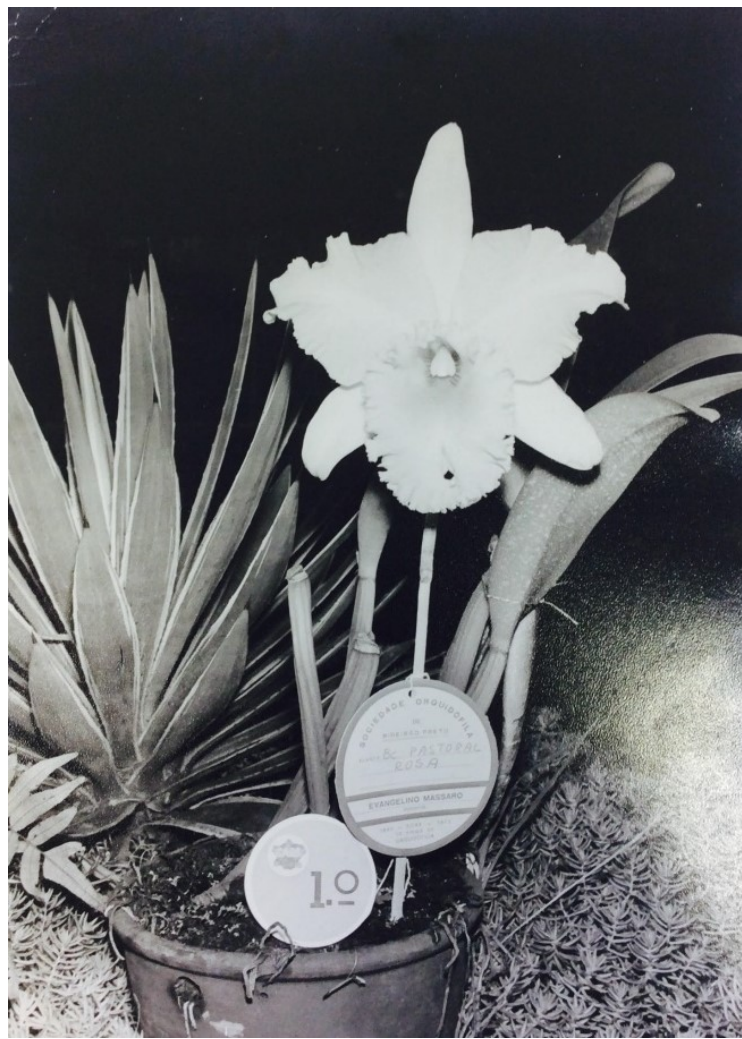

Fonte: Reprodução do original, acervo da UEIM.

Com base na Figura 1, os metadados de assunto foram registrados pelos alunos, conforme o Quadro 1.

Quadro 1 - Metadados de assunto da Figura 1

\begin{tabular}{|l|l|}
\hline Metadados & Descrição \\
\hline $\begin{array}{l}\text { Resumo } \\
\text { (PMEST) }\end{array}$ & $\begin{array}{l}\text { A fotografia retrata a 1a colocada da Exposição de Orquídeas da Festa } \\
\text { do Clima, de 1973, na cidade de São Carlos, estado de São Paulo. O } \\
\text { título foi atribuído à orquídea com espécie Bc. Pastoral Rosa, cultivada } \\
\text { e de reponsabilidade do orquidófilo Evangelino Massaro, da Sociedade } \\
\text { de Ribeirão Preto, estado de São Paulo. O autor da fotografia não foi } \\
\text { identificado. }\end{array}$ \\
\hline $\begin{array}{l}\text { Palavras- } \\
\text { chave }\end{array}$ & $\begin{array}{l}\text { Orquídeas; Bc. Pastoral Rosa; Exposição de Orquídeas; Festa do } \\
\text { Clima; Evangelino Massaro }\end{array}$ \\
\hline
\end{tabular}

Fonte: Elaborado pela autora.

Seguindo as instruções de Panofsky (1979), Shatford (1986), Smit (1989), Kossoy (2001), Manini (2001) e Maimone e Gracioso (2007), o resumo foi composto tentando abranger o máximo de informações encontradas, utilizando o Quem? (seres), Onde? (espaço), Quando? (tempo), Como? 
(técnica) e $\mathrm{O}$ quê? (ação). Selecionaram-se as palavras-chave a partir do resumo, e assim, destacando a prioridade para cada uma delas, foram escolhidos de três a seis termos, ponderando quantos conseguiram ser identificados.

\section{CONSIDERAÇÕES FINAIS}

Entre os apontamentos já realizados durante o trabalho ressalta-se que o ensino da representação temática de fotografias é um processo subjetivo, o que dificulta para que os alunos compreendam os desdobramentos além da sala de aula, pois implica a experiência e o conhecimento prévio de cada estudante, e sua instintividade e curiosidade para se aprofundar na análise da imagem.

Além disso, elucida que a análise documental, os vocabulários controlados e os tesauros aumentam a consistência dos metadados nos sistemas de recuperação para a localização, acesso, uso e reuso de fotografias em bancos de dados, catálogos e outras formas de armazenamento imagético.

Nesse sentido, é importante que os profissionais da informação discutam seriamente a necessidade da utilização de formas mais estruturadas para o preenchimento dos metadados de assunto, bem como discutam com seus principais usuários, os fotógrafos e demais especializados, uma transformação dos termos naturalmente usados para que o sistema funcione melhor e reflita a interlocução entre ambos.

Portanto, a utilização de estruturas terminológicas, hierárquicas ou não, fornece ferramentas importantes para a recuperação de recursos imagéticos, estejam eles em diferentes lugares ou em diferentes idiomas, e isso poderá acarretar novas propostas, cada vez mais tecnológicas, para a vinculação e relacionamento de registros.

\section{AGRADECIMENTOS}

Ao financiamento da Pró-Reitoria de Extensão (ProEx), da Universidade Federal de São Carlos (UFSCar).

Inf. Inf., Londrina, v. 22, n. 2, p. 532 - 545, maio/ago., 2017. 


\section{REFERÊNCIAS}

BOCCATO, V. R. C.; FUJITA, M. S. L. Discutindo a análise documental de fotografias: uma síntese bibliográfica. Cadernos BAD, s/v, n. 2, p. 84-100, 2006.

. RUBI, M. P.; FUJITA, M. S. L. Aplicabilidade de vocabulário controlado na análise documental de fotografias: uma prática possível. In: SOUZA, L. M. A.; FUJITA, M. S. L.; GRACIOSO, L. (Org.). A imagem em Ciência da Informação: reflexões teóricas e experiências práticas. Marília: Oficina Universitária; Cultura Acadêmica, 2014, p. 117-152.

CASTRO, C. A. A pesquisa discente nos cursos de graduação em Biblioteconomia e Ciência da Informação. Transinformação, Campinas, v. 14, n.1, p.49-53, jan./jun. 2002. Disponível em: <http://www.scielo.br/pdf/tinf/v14n1/06.pdf>. Acesso em: 15 mai. 2016.

COSTA, L. S. F. Uma contribuição da teoria literária para a análise de conteúdo de imagens publicitárias do fim do século XIX e primeira metade do século $X X$, contemplando aspectos da natureza brasileira. 2008. Tese (Doutorado em Ciência da Informação) - Universidade Estadual Paulista "Júlio de Mesquita Filho", Faculdade de Filosofia e Ciências, 2008.

DAL'EVEDOVE, P. R.; FUJITA, M. S. L. O conhecimento profissional do catalogador de assunto sobre política de indexação em bibliotecas universitárias. Revista Digital de Biblioteconomia e Ciência da Informação, v. 11, n. 2, p. 21-39, 2013. Disponível em:

<http://www.sbu.unicamp.br/seer/ojs/index.php/rbci/index>. Acesso em: 15 mai. 2016.

DALY, T. The fundamentals of digital photography. Londres: A\&C Black, 2014.

FUJITA, M. S. L. (Org.) A indexação de livros: a percepção de catalogadores e usuários de bibliotecas universitárias. São Paulo: Cultura Acadêmica, 2009. Disponível em: <http://www.culturaacademica.com.br/catalogodetalhe.asp?ctl id=56>. Acesso em: 15 mai. 2016.

GIL, A. C. Metodologia da pesquisa. São Paulo: Atlas, 2002.

HARPRING, P. Introduction to controlled vocabularies: terminology for art, architecture, and other cultural works. Los Angeles: Getty Publications, 2010.

HEARST, M. et al. Faceted metadada for image search and browsing. Berkeley: University of California, 2007.

KOSSOY, B. Fotografia \& história. São Paulo: Ateliê, 2001. 
MAIMONE, G. D.; GRACIOSO, L. S. Representação temática de imagens: perspectivas metodológicas. Informação \& Informação, Londrina, v. 12, n. 1, 2007. Disponível em:

$<$ http://www.uel.br/revistas/uel/index.php/informacao/article/view/1760>. Acesso em: 15 mai. 2016.

MANINI, M. P. Análise documentária de imagens. Informação \& Sociedade, João Pessoa, v. 11, n. 1, 2001. Disponível em:<http://www.ies.ufpb.br/ojs2/index.php/ies/index>. Acesso em: 15 mai. 2016.

PANOFSKY, E. Significado nas artes visuais. 2. ed. São Paulo: Perspectiva, 1979.

RODRIGUES, R. C. Análise e tematização da imagem fotográfica: determinação, delimitação e direcionamento dos discursos da imagem fotográfica. 2011. Tese (Doutorado em Ciência da Informação) - Universidade de Brasília, 2011.

SHATFORD, S. Analyzing the subject of a picture: a theoretical approach. Cataloging \& Classification, v. 6, n. 3, p. 39-62, 1986.

SIMIONATO, A. C. Aspectos dos metadados de assunto na catalogação de fotografias. In: GUIMARÃES, J. A. C.; DODEBEl, V. (Org.). Organização do conhecimento e diversidade cultural. Marília: ISKO-Brasil; FUNDEPE, 2015, v. 1 , p. $154-162$.

Representação, acesso, uso e reuso da imagem digital. 2012. Dissertação (Mestrado em Ciência da Informação) - Universidade Estadual Paulista “Júlio de Mesquita Filho", Faculdade de Filosofia e Ciências, 2012.

SMIT, J. W. A análise da imagem: um primeiro plano. In: SMIT, J. W. (Org.) Análise documentária: a análise da síntese. Brasília: IBICT, 1989.

. A representação da imagem. Informare: cadernos do Programa de Pós-graduação em Ciência da Informação, v. 2, p. 28-36, 1996.

Title

Methods of subjects in photographs analysis: study on information of representation in education ambit

Abstract:

Introduction: The photographic is considered by your historical value and for its own direct reality elements that are transmitted by your visual syntax. It is proposed that the reflection of how the methods of analysis of subject in photographs must be part of the composition of the teaching of courses in Library and Information Science of Federal

Inf. Inf., Londrina, v. 22, n. 2, p. 532 - 545, maio/ago., 2017. 
University of São Carlos (UFSCar). Objective: This paper is to present an overview of the main guidelines for the assignment of subject metadata value in treating photographs, entered the graduate education of library and information science. Methodology: For bibliographic survey conducted about the guidelines addressed photo representation, subsidizing the theoretical nature, exploratory and qualitative work Results: The results show that features the subject feature a range of possibilities and that, even so, I remove the subjectivity of an image. Conclusions: Thus, the use of tools and guidelines for content increases the consistency of the metadata of subject to localization systems, access, use and reuse of photographs, in databases, catalogs and other forms of imagery storage.

Keywords: Photographic. Subject analysis. Organization of information. Representation of the information. Image.

\section{Titulo}

Métodos de análisis del tema en fotografías: estudio de la enseñanza de la representación de la información

\section{Resumen:}

Introducción: El documento fotográfico es considerado por su valor histórico y por sus propios elementos de la realidad directa que son transmitidos por su sintaxis visual. Se propone que la reflexión de cómo los métodos de análisis del tema en las fotografías deben ser parte de la composición de la enseñanza de cursos en biblioteca y Ciencias de la información en la Universidad Federal de São Carlos (UFSCar). Objetivo: El objetivo de este trabajo es presentar un resumen de las principales directrices para la asignación de valor de metadatos de objeto en el tratamiento de fotografías, entró en el posgrado de Bibliotecología y Ciencias de la información. Metodología: la encuesta bibliográfica acerca de las directrices dirigidas representación foto, subsidiando la naturaleza teórica, trabajo exploratorio y cualitativo. Resultados: los resultados muestran que el tema cuenta con una gama de posibilidades y eliminar la subjetividad de una imagen. Conclusiones: el uso de herramientas y directrices para el contenido aumenta la coherencia de los metadatos de objeto de sistemas de localización, acceso, uso y reutilización de fotografías, en las bases de datos, catálogos y otras formas de almacenamiento de imágenes.

Palabras clave: Fotografía. Análisis de tema. Organización de la información. Representación de la información. Imagen.

Recebido: 30.08 .2017

Aceito: 30.09 .2017

Inf. Inf., Londrina, v. 22, n. 2, p. 532 - 545, maio/ago., 2017. 